\title{
The Source of the Cadet Negative Emotions and Countermeasures
}

\author{
Yaozhong Liu, Xiaofang Liu \\ Management School, Jinan University, Guangzhou, China \\ Email: 602480031@qq.com
}

Received 15 July 2016; accepted 9 August 2016; published 12 August 2016

Copyright (C) 2016 by authors and Scientific Research Publishing Inc.

This work is licensed under the Creative Commons Attribution International License (CC BY). http://creativecommons.org/licenses/by/4.0/

c) (i) Open Access

\begin{abstract}
Because of more complex environment and the heavy study and training tasks, the cadets are more vulnerable to the attack of negative emotions that affect their psychological health. It is vitally significant to focus attention on the negative emotions and cadets active coping measures, which are proposed to improve the mental health. In this paper, the cadets' negative emotions system research, analyses of the cadet negative energy source and the corresponding countermeasures are put forward.
\end{abstract}

\section{Keywords}

Cadets, Negative Emotions, Source, Countermeasures

\section{Introduction}

Cadets are an important force in the future national defense construction, and play an important role in the building of the national security [1]. But with the development of the society, cadets face more brutal information-based war, therefore, in the reform of military academy cadets put forward higher request, not only need to strengthen the strain of military training, improve the combat effectiveness, but also need to further strengthen professional knowledge learning, improve the quality of the military. Nervous demanding frequent, point strict management, training and learning of cultural knowledge also dare not relax. Pointing hard life makes cadets especially newly enrolled new students often fail to adjust to life in the military academy and produce negative emotions [2]. Even the old students due to its source in the face of setbacks more widely are easy to fall into negative emotions, therefore, their degree of negative emotional state and mental health is eager to be focused.

Mood is a personal mental outlook and an attitude behavior of effective reaction [3]. We can say that is a barometer of psychological well-being. That a person is in the negative emotion for a long time will cause a series 
of psychological problems, which is bad to mental health [4]. Negative emotions pose a great threat to health of body and mind. In the long run, positive attention to cadet negative emotions to their mental health is very good. So in this paper, the negative emotions of cadet's system research, its purpose is to analyze the source of negative emotions of cadets so as to put forward the countermeasures of promoting cadets psychological health development.

\section{The Source of the Cadet Negative Emotions}

Along with the social constant development and the social interest structure adjustment, social demands for cadets' quality and military training mission also gradually increase. Cadets in school learning process and daily life are often faced with more and more contradictions and conflicts, to bear more and more psychological pressure. Sources of their negative emotions are diversified [5]. So exploring the source of the cadet negative emotions, which is beneficial to put forward countermeasures to manage cadet negative emotions, and it is advantageous to the cadet pressure. It will improve the psychological well-being of cadet and maintain the stability and improve the army's combat effectiveness. It will also improve the whole quality of the team and the overall positive outlook. Combined with the characteristics of the military academy cadets and environment characteristics, we can conclude that the cadet negative energy source mainly comes from the following aspects:

\subsection{The Pursuit of Progress and Caused the Huge Gap between Reality}

Most cadets are through strict selection; they come from all over the country's outstanding groups, although the age is small, it has a great ideal. In addition, in Chinese society, admission to the academy is the glory of the family or even is the honor of a place. They carry hope and glory from family and other people. So, they are aggressive in the military academy, eager to achieve ideal ambitious and eager to pursue success [6] [7]. Because of more fierce competition after entering the military school, however, which can be said to be the competition between the strong, many cadets at that time is difficult to achieve their own personal wishes. In the competition between the strong and the strong, they will encounter so many difficulties and setbacks. In long-term frustration stress situation it is very prone to have negative emotions, such as low self-evaluation, lost, despair and depression.

But due to the military school pays more attention to the positive emotion, individual students are afraid of leading cadres finding this kind of negative emotion. The negative emotion often can't be shown, and it's depressed for a long time. So the cadets will be in a self-denial and hated condition [8]. Some students produce the idea of suppression, malaise and abandon. Even some students cannot correctly treat the negative emotion, they can produce psychological distortion to a certain extent, and they will regard the student who wins in the organization as the enemy, and even take action hurt each other.

\subsection{Has Not Been Able to Adapt to High Strength Army Life}

Military academy is to foster high quality troops. They not only need to learn cultural knowledge, but also need to accept strict military training [9]. The point of environment is very difficult, and point management is strict, and military training is very hard. But because of the social improvement of living standards, the majority of students grow up in a rich material and advantageous environment; we can say that they nearly taste what is bitter and what is a setback, so they don't develop the spirit of bearing hardships and standing hard work. Once in the military academy, compared with the usual comfortable life, they often lack of resilience, resulting in a tense and fearful emotion. And in the military academy, in addition to very strict military training, it also emphasizes ideological and political learning, so students tend to produce bigger gaps, feeling not adapt to the military school life [10]. Due to military school leadership managements have heavy tasks, they hardly dope out students negative emotion, and if not in time to eliminate these negative emotions will lead to students appear to feel exhaustion of body and mind, resulting in a reverse psychology.

\subsection{Social Climate Cause Psychological Unbalance}

With the continuous development of economy, people's living standards continue to improve, thus accompanied by certain social problems. This bad atmosphere in life often also can cause some erosion of cadets, makes determination to waver. Cadets who are once stained with this kind of life atmosphere and are intoxicated tend to 
blame hardships to the point of life, and produce unfair treatment; a soldier will produce lackadaisical psychology in learning and training [11]. And because of a series of military reform, heavier and heavier military training task for cadets at present, higher and higher requirements of safety management, the physical and psychological pressure caused by the military academy is becoming bigger and bigger, which causes psychological burnout of cadets. Compared with the military school comfortable life at university, a huge contrast produces psychological unbalance, irritability, depression and exhaustion of body and mind [12].

\subsection{Major Sudden Event Cause Bad Feelings}

Due to the nervous learning and training at ordinary times, cadets often have little time to care about their families or friends, even after the accidents they can't timely offer help for family, so that it can aggravate the cadets' feeling of guilt, and cadets can even appear wrong attribution, thinking that if they can do something for these accidents, they will not happen. This will increase the psychological pressure of cadets in the face of these accidents, and increase the duration of the negative emotion experience. This will make more complex psychological condition of the cadets, so that they will lose confidence to the life and their own choices, or even be pessimistic.

\section{The Harm of Negative Emotions}

Negative emotions will produce extensive damage. The article discusses this from two aspects: organizational level and individual level. The first is from the organization level. Students in the organization if they are in a negative mood are sure to affect the atmosphere of the organization, especially, the mood is very easy to be infected, and studies have shown that negative feelings pass faster than positive emotions [13]. Academy is a place full of strength. Cadets are also a positive energetic group. They are the important guarantee for the future development of the motherland, therefore, if the cadets' negative emotion cannot be eliminate effectively, it will affect the organization's atmosphere, making the organization repressive and full of negative energy, and also making the students feel negative to learning and life, which will also affect the organization's fighting force. Even in the long run, it will also affect the future combat forces in our country.

Secondly, negative emotions will bring influence and harm to the individual. The mood belongs to a person, especially as a cadet, once the negative emotions are less able to show, the harm he brings to individual will be greater. This article will analyze the harm of negative emotions which bring to the individual from the following several aspects:

\subsection{Reduce an Individual's Quality of Life}

Emotions are the carrier of individual mental reaction, such as sunlight or air that follows people together. A long time negative emotion will affect individual work and life. For cadets, negative emotions can seriously interfere with their learning process, making their talent is not able to fully play out. But for such a competitive military academy which needs to learn advanced knowledge industriously, once learning behind others, it will more easily lead to negative emotions such as anxiety and depression, and it will further increase the psychological pressure. So, a vicious circle can greatly reduce a person's quality of life and increase the mental burden.

\subsection{Negative Emotions Lead to Formation of Cognitive Biases}

Once people are surrounded by negative emotions, they are easy to view things with colored glasses, and often easy to be fooled by the appearance of things, and then form the wrong cognition [14]. A negative mood also tends to make larger change in people's attitude towards things, and they will be more often in a negative attitude towards other people and things. Negative emotions will often seriously affect the interpersonal relationship. No one is willing to make friends with people who are vulnerable and bland all day. And in the middle of a negative emotion, it is often difficult to accept other people and to be accepted, so negative emotion can often cause bad relationships.

\subsection{Negative Emotions, Harmful to Health of Body and Mind}

Studies have shown that psychological factor is one of the important reasons that lead to physical illness. Physi- 
cal and mental are interaction. Mutual promotion of mental health is conducive to the health of the body, but the poor mental health status can also cause the disease of the body. It even may activate the latent disease factors and threaten individual's physical and mental health [15]. Negative emotions are unfavorable to the cultivation of healthy personality. Long-term negative emotions can lead to negative cognition, and cadets will lack positive understanding of objective things. The period of university students is the key to shape good personality, so the long-term negative emotions can also be an important impact on the formation of a personality.

\subsection{Interfere With the Learning Process}

Positive emotions are the motivation to promote learning, but negative emotions will influence the full play of the intellect. Psychology is good, optimistic and cheerful; the brain is easy in the activated and excited state, so cadets will be able to learn creatively. On the other hand, intellectual levels may drop. At the same time, the mood can also affect the learning attitude. In high spirits, they will encourage people to explore the research. On the other hand, they will refuse to struggle and give up study.

\subsection{In Conducive to Establish a Good Interpersonal Relationship}

In general, indifferent, fragile and nervous psychology itself has closed characteristic, which is difficult to accept others and also difficult to be accepted by others. Therefore, people who are in bad mood will be in poor interpersonal relationship and will be more melancholy. They tend to lack friends and feel lonely and lost many opportunities for development.

\section{Cadets Management Countermeasures of Negative Emotions}

Our life always meets with setbacks, and suffering negative emotions is always inevitable. But the most important thing is to realize their negative emotions clearly, as well as the source of the negative emotions and their harm, and on this basis to take active measures to negative emotions. Aimed at the source of the cadet negative emotions, we can take the following measures to actively respond to:

\subsection{Cultivate the Spirit of the Bear Hardships and Stand Hard Work, Positive and Optimistic Attitude}

Emotional regulation is that the events of the cognition and attitude determine a person's mood on this matter. For the same events, different cognitive styles will have different mood, like facing half cup of water. Optimistic people luckily rejoice they have half cup of water while pessimistic people only have half cup of water. Therefore, training cadets to adjust the negative emotions with correct cognition of things can play an important role.

The most important thing is to cultivate the spirit of the bear hardships and standing hard work, when in the face of setbacks and difficulties they can go on. They should also pay attention to improve the cadet's compressive ability and strengthen the psychological quality. Strong heart is one of the important strengths to resist negative emotions. Making use of education guidance, the collective environment, and self cultivation and so on to strengthen the cadets' psychological adaptation to the life in the military education, and to overcome the adverse psychological guidance education and cultivate their healthy personality, confidence, resistant ability and creation ability.

\subsection{To Strengthen the Mental Health Education}

In military academy education, the most important is the ideological and political education. Although a lot of people resist for the political education, the ideological and political education is also one of the important conditions of strengthening the psychological quality. So it is essential to strengthen the patriotic education of the cadets, helping them establish a correct outlook on life and at the same time strengthen the cadets' mental health education and providing psychological counseling and treatment services for cadets. For example, schools can hold some lectures about psychological health knowledge for cadets, making the students have a certain understanding and master to the mental health. They should have a positive self-understanding. When suffering from negative emotions, they can adjust their emotion positively, and learn to adapt to the environment, then build harmonious and interpersonal relationship, thus reducing the pressure, so as to overcome the negative emotions. 


\subsection{Establish a Daily Negative Emotional Guidance System}

Studies show that when people are faced with psychological pressure and have adverse psychological reactions, most people only have mild psychological problems; they talk to the familiar who around them, then the problems can be significantly reduced. Cadets in their daily lives are hit by negative emotions more often, so in daily life it's very necessary to build related negative mood dredge mechanisms. Paying positive attention between students and being patient to listen help troubled students cope with negative emotions. Maybe the tiny system to alleviate the negative emotion of students can play the effective role, while cadres should pay positive attention to students who are not good at expression, pay special attention to the emergence and development of their negative emotions, and actively provide the corresponding help, in order to avoid serious consequences to which the accumulation of long-term negative emotions leads. Students who are in the middle of negative emotions for a long time should seek professional psychological consultants for help.

\subsection{Cultivate Correct Way of Attribution}

Incorrect attribution will lead to a wrong cognition of things. For example, when suffering from learning misery, if the study result is not ideal, the individual attributes the cause to their own IQ problems then tends not to take active measures while they are easier to abandon themselves instead. In the face of frustration, we should make them form the correct cognition, and make them understand that failure is a stepping stone to success. In the face of setbacks, attitude can also lead to different results. People should have a common mind to treat setbacks and have the courage to face setbacks and overcome them, then be a real powerhouse.

\section{Conclusion}

This article selects cadets the special group of negative emotions as the research object from the emotional to make us better understand the negative emotions of the existence and the impact to the people, combines the characteristics of military academy cadets and environment characteristics and analyzes the source of the cadet negative emotion and negative emotional damage. Finally for the cadet how to actively respond to negative emotions, we put forward some suggestions and countermeasures.

\section{References}

[1] Yang, H.Z. (2010) Military Management Revolution Theory. Military Publishing House, Beijing, 131-132.

[2] Xu, J.C., Gu, Y.X. and Yang, X.Y. (2010) Common Psychological Problems of College Freshmen in the Process of Their Military Training and Coping Strategies. Journal of Heilongjiang Province Ecological Engineering Vocational College, 23, 86-87.

[3] Chen, Y. (2014) Cadets of Military Training Management Research. China's School Education, 12, 26-28.

[4] By the Fijian (2009) Military Training Queue Training Middle School Student Is Analyzed Causes and Countermeasures of Mood Disorders. Journal of Network of Wealth, No. 4, 24-2.

[5] Shen, Y.X. (2008) Solve Students' Military Training in the Negative Emotion. Journal of Moral Education in China, No. 2, 17-19.

[6] Leudon (2011) Different Types of Cadet's Psychological Health Condition Investigation and Study. The Campus Psychology, 9, 149-151.

[7] Yang, G.X. (2000) The Unhealthy Feelings of the University Students' Psychological and Harm. Journal of Henan University of Technology (Social Science Edition), 6, 353-354.

[8] Fu, C.A., Li, Y., et al. (2011) The Recruit Training Anxiety Depression Mood Changes during the Period of Investigation and Analysis. National Medicine, 23, 2182-2183.

[9] Zhang, D.J. and Wang, X.J. (2012) Mental Health and Psychological Quality of the Relationship: Connotation structure Analysis. Journal of Southwest University, 42, 69-74.

[10] Ceng, Y.Q. (2009) College Students' Negative Emotions and Adjustment. Journal of Guizhou Normal University (Social Science Edition), No. 3, 104-106.

[11] Shen, Y.X. (2013) To Release the Negative Emotions. China’s Moral Education, No. 2, 17-19.

[12] Clayman, L.R. (2007) Contemporary Education Psychology. Beijing Normal University Press, Beijing.

[13] Zhang, P.Y. (2010) College Students’ Negative Emotions, Causes and Countermeasures to Redistribute. Journal of 
Ideological Education Research, No. 1, 35-37.

[14] Julius (2009) The Anxiety Status of Freshmen in the Process of Their Military Training and Coping Strategies. Journal of Beijing Urban Science, No. 8, 84-89.

[15] Sun, J.Y., Ye, C.L., et al. (2013) The Group Psychological Training of Cadet’s Psychological Health Level. The Influence of Chinese Journal of Health Psychology, 21, 46-48.

Submit or recommend next manuscript to SCIRP and we will provide best service for you:

Accepting pre-submission inquiries through Email, Facebook, LinkedIn, Twitter, etc.

A wide selection of journals (inclusive of 9 subjects, more than 200 journals)

Providing 24-hour high-quality service

User-friendly online submission system

Fair and swift peer-review system

Efficient typesetting and proofreading procedure

Display of the result of downloads and visits, as well as the number of cited articles

Maximum dissemination of your research work

Submit your manuscript at: http://papersubmission.scirp.org/ 